\title{
Threatened retaliation as an inhibitor of human aggression: Mediating effects of the instrumental value of aggression
}

\author{
ROBERT A. BARON* \\ Purdue University, Lafayette, Indiana 47907
}

\begin{abstract}
Sixty male undergraduates participated in an experiment designed to investigate the hypothesis that threatened retaliation from the victim would be highly effective in inhibiting subsequent aggression under conditions where the instrumental value of such behavior was low, but would be relatively ineffective in this regard under conditions where the instrumental value of such actions was high. Support was obtained for both of these predictions. Findings were discussed in terms of their implications with respect to the usefulness of threatened punishment as a means of preventing or controlling human violence.
\end{abstract}

It has frequently been contended that threatening potential aggressors with punishment for the perpetration of aggressive acts may be a highly effective means of inhibiting the occurrence of such behavior (see, e.g., Dollard, et al, 1939; Walters, 1966). In view of the apparently general acceptance of this belief, it might be assumed that it is based upon the findings of an extensive body of research. Surprisingly, however, this is far from the case. Indeed, only a small number of experiments have sought to examine the aggression-inhibiting influence of threatened punishment, and even the findings of these studies have been somewhat inconclusive. Thus, while several recent investigations have reported that threatened punishment is indeed effective in inhibiting human aggression (e.g., Baron, 1971; Shortell, Epstein, \& Taylor, 1970), other experiments have failed to substantiate the occurrence of such effects (Baron, 1973; Knott \& Drost, 1972). The inconsistent findings of these studies, coupled with the informal observation that threatened punishment sometimes succeeds, and sometimes fails in inhibiting overt aggression in various situations outside the laboratory, suggest very strongly that the influence of this variable is mediated by several additional factors. The present experiment was designed to investigate the influence of one such factor, that of the instrumental value of aggression.

As noted recently by Buss (1971), aggression often serves as an instrumental response, providing its perpetrators with many important forms of reward (e.g., money, status, prestige). It is suggested here that to the extent this is the case (i.e., to the extent aggression possesses such instrumental value), threatened punishment will be ineffective in preventing or inhibiting the occurrence of such behavior. More specifically, it is proposed that other factors being equal, threatened

*The author wishes to express his sincere appreciation to Jack Gay, Sharon Jackson, Patti Rostkowski, and Dennis McGuire for their able assistance in the collection of the data, and to Paul Bell for his aid in the statistical analyses. Requests for reprints should be sent to the author at the Department of Psychological Sciences, Purdue University, West Lafayette, Indiana 47907. punishment will be highly effective in inhibiting subsequent aggression under conditions where the instrumental value of such behavior is low, but relatively ineffective in this regard under conditions where its instrumental value is high.

\section{METHOD}

\section{Subjects and Design}

Sixty undergraduate males enrolled in sections of elementary psychology at Purdue University participated in the experiment. Ss took part in the study in order to satisfy a course requirement. A 3 by 2 factorial design, based upon three levels of apparent probability of retaliation from the victim (low, moderate, high) and two levels of instrumental value of aggression (low, high), was employed. Ten Ss were randomly assigned to each cell of this design.

\section{Apparatus \\ The apparatus consisted of modified Buss "aggression machine" (Buss, 1961) identical to that employed in a number of previous investigations (e.g., Baron, 1971, 1973). This device contained 10 push-button switches which could ostensibly be employed by Ss to deliver electric shocks of varying intensity to another individual.}

\section{Procedure}

When Ss arrived for the experiment, they found a confederate already present in the waiting room. Shortly thereafter, the E arrived and conducted both individuals to the experimental room where she explained that the study was concerned with the effects of aversive stimuli (in this case, electric shock) on physiological reactions (see Baron \& Eggleston, 1972). The S was then chosen to deliver 20 shocks of whatever intensity he desired to the confederate so that, presumably, this individual's reactions to such stimuli could be carefully investigated. Since Ss were informed that they were entirely free to employ any shocks they wished, the main dependent measure of aggression was the strength of the shocks they selected to use. Of course, the confederate never actually received any shocks during the experiment.

Instrumental Value of Aggression. The instrumental value of aggression was varied by informing Ss in the high instrumental value group that previous research had revealed the existence of a close relationship between the strength of Ss' tendencies to employ high-magnitude shocks and their level of masculinity and general maturity, while omitting such instructions for Ss in the low instrumental value condition. Thus, as has been the case in 
Table 1

Mean Intensity of Shocks Delivered to the Responder by Subjects in Six Groups

\begin{tabular}{ccc}
\hline \multirow{2}{*}{$\begin{array}{c}\text { Apparent } \\
\text { Probability } \\
\text { of Retaliation }\end{array}$} & \multicolumn{2}{c}{$\begin{array}{c}\text { Instrumental Value } \\
\text { of Aggression }\end{array}$} \\
\cline { 2 - 3 } & Low & High \\
\hline Low & $4.90_{\mathrm{b}}$ & $5.84 \mathrm{~b}$ \\
Moderate & $4.88_{\mathrm{b}}$ & $4.95 \mathrm{~b}$ \\
High & $3.66_{\mathrm{a}}$ & $5.16_{\mathrm{b}}$ \\
\hline
\end{tabular}

Note-Means that do not share a common subscript differ significantly at the .05 level by Duncan multiple range test.

previous studies (e.g., Buss, 1966), Ss in the high instrumental value group were led to believe that they could obtain an important goal (in this case, that of "looking good" in the experiment) by directing strong shocks against the confederate, while those in the low instrumental value group were not informed of the existence of such a contingency.

Apparent Probability of Retaliation. The apparent probability that Ss would ever be exposed to retaliation from the confederate was varied by informing those in the low probability group that the confederate would never have an opportunity to shock them, those in the moderate probability group that he might have such an opportunity, and those in the high probability group that he definitely would be provided with such an opportunity. In reality, however, Ss never changed places with the confederate, and never received any shocks from this individual.

\section{RESULTS}

Table 1 presents the mean intensity of the shocks delivered to the confederate by Ss in each of the six experimental groups. Inspection of this table suggests that the level of shocks directed against this person was influenced both by the instrumental value of aggression, and the apparent probability of retaliation. More specifically, Ss in the high instrumental value group delivered stronger shocks to the victim than Ss in the low instrumental value group, and the strength of the shocks they employed tended to decrease as the apparent probability of retaliation rose. In addition, and of somewhat greater interest within the context of the present research, these two independent variables appeared to interact in the predicted manner, so that aggression was sharply inhibited by a high apparent probability of retaliation in the low instrumental value group, but was not similarly reduced by such conditions in the high instrumental value group.

An analysis of variance performed upon the data represented in Table 1 yielded significant main effects for instrumental value of aggression $(F=7.78, \mathrm{df}=1 / 54$, $\mathrm{p}<.01)$, and apparent probability of retaliation $(\mathrm{F}=$ 4.09 , df $=2 / 54, p<.025)$. Thus, as suggested by Table 1, Ss in the high instrumental value condition delivered significantly stronger shocks to the responder than Ss in the low instrumental value condition, and the level of shocks directed against this person tended to decrease as the apparent probability of retaliation rose. In addition, the interaction between instrumental value of aggression and apparent probability of retaliation closely approached conventional levels of statistical significance $(F=2.99, \mathrm{df}=2 / 54, \mathrm{p}=.056)$. In order to examine this apparent interaction more closely, the means of the six groups were compared by Duncan multiple range test. The results of this analysis indicated that in the case of the low instrumental value condition, the mean of the high probability group was significantly smaller than those of both the low and moderate probability groups $(p<.05)$, while in the case of the high instrumental value condition, there were no significant differences between the means of the high, moderate, and low probability groups. Apparently, then, threatened punishment (in the form of retaliation from the victim) was effective in inhibiting subsequent aggression only under conditions where such behavior was relatively low in instrumental value.

\section{DISCUSSION}

The results of this experiment suggest that the effectiveness of threatened punishment in inhibiting human aggression is influenced, to an important degree, by the instrumental value of such behavior. More specifically, it was found that a high apparent probability of retaliation from the victim was quite successful in inhibiting subsequent aggression by Ss in the low instrumental value group, but relatively ineffective in preventing such behavior by Ss in the high instrumental value condition. Thus, it appears that this form of threatened punishment may serve as an effective deterrent to human aggression only under conditions where potential aggressors have relatively little to gain in the way of extrinsic rewards from the performance of such actions.

That the aggression-inhibiting impact of threatened retaliation may be substantially diminished by raising the instrumental value of such behavior is not in itself very surprising. After all, informal observation suggests very clearly that aggressors will of ten persist in their attacks against others, even in the face of severe threats of punishment, under conditions where the attainment of important rewards is made contingent upon such actions (see, e.g., Buss, 1966, 197.1). What is surprising, however, is the fact that the influence of threatened punishment could be markedly diminished in the present study by procedures which presumably induced only a modest increment in the instrumental value of aggression. This finding seems to suggest that threatened punishment may be much less effective as a technique for preventing human violence than has previously been suggested (e.g., Walters, 1966), serving to substantially inhibit such behavior only under conditions where its instrumental value is quite low.

That threatened punishment may be of rather limited use in deterring human aggression is also suggested by the finding that even under conditions of low instrumental value, attacks against the victim were substantially reduced only when direct retaliation from this person appeared to be a virtual certainty (i.e., only in the high probability group). In view of these results, it seems unwise to assume, as has often been the case (e.g., Walters, 1966), that threats of punishment will always, or even generally, serve as an effective means of inhibiting overt violence. Rather, it seems more reasonable to attempt, in future research, to specify those conditions under which threatened punishment will, or will not succeed in accomplishing this important task.

\section{REFERENCES}

Baron, R. A. Exposure to an aggressive model and apparent probability of retaliation from the victim as determinants of 
adult aggressive behavior. Journal of Experimental Social Psychology, 1971, 7, 343-355.

Baron, R. A. Threatened retaliation from the victim as an inhibitor of physical aggression. Journal of Experimental Research in Personality, 1973, 7, 103-115.

Baron, R. A., \& Eggleston, R. J. Performance on the "aggression machine": Motivation to help or harm? Psychonomic Science, $1972,26,321-322$.

Buss, A. H. The psychology of aggression. New York: Wiley, 1961.

Buss, A. H. Instrumentality of aggression, feedback, and frustration as determinants of physical aggression. Journal of Personality \& Social Psychology, 1966, 3, 153-162.

Buss, A. H. Aggression pays. In J. L. Singer (Ed.), The control of aggression and violence. New York: Academic Press, 1971.
Dollard, J., Doob, L. W., Miller, N. E., Mowrer, O. H., Sears, R. R. Frustration and aggression. New Haven: Yale University Press, 1939.

Knott, P. D. \& Drost, B. A. Effects of varying intensity of attack and fear arousal on the intensity of counter aggression. Journal of Personality, 1972, 40, 27-37.

Shortell, J., Epstein, S., \& Taylor, S. P. Instigation to aggression as a function of degree of defeat and the capacity for massive retaliation. Journal of Personality, 1970, 38, 313-328.

Walters, R. H. Implications of laboratory studies of aggression for the control and regulation of violence. Annals of the American Academy of Political \& Social Science, 1966, 364, 60-72.

(Received for publication December 7, 1973.)

\title{
Influence of reward magnitude on the initial nonreward effect*
}

\author{
E. J. CAPALDI $\dagger$ and STEVEN J. HAGGBLOOM \\ Purdue University, West Lafayette, Indiana 47907
}

\begin{abstract}
Two groups received 20 nonrewarded $(\mathrm{N})$ runway trials followed by either 20 small-reward ( 2 pellets) or 20 large-reward (20 pellets) trials (Groups $\mathrm{N}-2$ and $\mathrm{N}-20$, respectively). Groups receiving 40 small-reward (Group 2-2) or 40 large-reward (Group 20-20) trials were also included ( $\mathrm{N}=10 \mathrm{rats} / \mathrm{group}$ ). An initial nonreward effect (INE) was obtained, with Groups N-2 and N-20 being more resistant to extinction than Groups 2-2 and 20-20, respectively. The size of the INE was independent of reward magnitude, and small-reward groups were more resistant to extinction than large-reward groups.
\end{abstract}

Groups given a block of nonrewarded trials, not preceded by rewarded trials (initial nonrewards), but followed by continuous reinforcement (CRF) have been found to be more resistant to extinction than groups given CRF alone (Robbirs, Chait, \& Weinstock, 1968; Spear, Hill, \& O'Sullivan, . 965; Spear \& Spitzner, 1967). The increased resistance to extinction ( $\mathrm{R}$ to $\mathrm{E}$ ) produced by initial nonrewards has been called the initial nonreward effect (INE). The studies cited above employed a substantial number of initial nonrewards, but a small-trial INE has been obtained when very few initial nonrewards and subsequent CRF trials were used (Capaldi \& Waters, 1970; Capaldi, Ziff, \& Godbout, 1970; McCain, 1966).

The purpose of the present experiment was to determine the effects of reward magnitude on the INE. As an initial nonreward-CRF sequence constitutes a form of partial reinforcement (PRF), it would be useful to know whether the INE and the partial reinforcement extinction effect (PREE) are similarly influenced by reward magnitude. Hulse (1958) and Wagner (1961) reported that under PRF, $\mathrm{R}$ to $\mathrm{E}$ was an increasing

*This research was supported in part by National Institute of Child Health Development Grant 5R HD 04379-03 to E. J. Capaldi.

TRequests for reprints should be sent to E. J. Capaldi, Department of Psychological Sciences, Purdue University, Lafayette, Indiana 47907. function of reward magnitude while under CRF, $\mathrm{R}$ to $\mathrm{E}$ was inversely related to reward magnitude. Hence, in those investigations, the PREE was larger with large reward than with small reward.

In the present experiment, the effects of reward magnitude were examined for groups shifted from nonreward in Phase 1 to either 2 or 20 pellets reward in Phase 2 . These groups were compared during extinction to groups given either 2 or 20 pellets reward in both Phase 1 and Phase 2.

\section{METHOD}

\section{Subjects}

The Ss were 40 naive male albino rats approximately 80 days old when received from the Holtzman Co., Madison, Wisconsin.

\section{Apparatus}

The apparatus consisted of a runway, $208.4 \mathrm{~cm}$ long $\mathrm{x}$ $22.9 \mathrm{~cm}$ high $\mathrm{x} 10.2 \mathrm{~cm}$ wide, with a hinged lid of $1.3-\mathrm{cm}$ hardware cloth; it was painted flat gray throughout. A 20.3-cm-long floor treadle suspended over a microswitch constituted the initial portion of the alley. When the treadle was depressed by the weight of the rat, the first .01-sec clock was started. The clocks were operated by photoelectric circuitry, with start, run, and goal times being measured over the first $5.1 \mathrm{~cm}$ beyond the forward edge of the treadle, the next over $132.1 \mathrm{~cm}$, and finally over a $39.4-\mathrm{cm}$ section, respectively. When the goal clock stopped, a brass guillotine door, $30.5 \mathrm{~cm}$ from the end of the runway, was manually lowered to prevent retracing. Two identical food cups were constructed by drilling two 